\title{
Using Technology to Improve the Interview as a Selection Tool
}

Brad A. Chambers

Polaris Assessment Systems

John D. Arnold

Polaris Assessment Systems

Follow this and additional works at: https://scholarworks.bgsu.edu/pad

Part of the Human Resources Management Commons, Industrial and Organizational Psychology Commons, and the Other Psychology Commons

How does access to this work benefit you? Let us know!

\section{Recommended Citation}

Chambers, Brad A. and Arnold, John D. (2015) "Using Technology to Improve the Interview as a Selection Tool," Personnel Assessment and Decisions: Number 1 : Iss. 1 , Article 7.

DOI: https://doi.org/10.25035/pad.2015.007

Available at: https://scholarworks.bgsu.edu/pad/vol1/iss1/7

This Practitioner Demonstration Project is brought to you for free and open access by the Journals at ScholarWorks@BGSU. It has been accepted for inclusion in Personnel Assessment and Decisions by an authorized editor of ScholarWorks@BGSU. 


\title{
Using Technology to Improve the Interview as a Selection Tool
}

\author{
Brad A. Chambers and John D. Arnold ${ }^{1}$ \\ 1. Polaris Assessment Systems
}

ABSTRACT

\section{KEYWORDS}

selection interviews, interview training, technology and interviewing

Using the extant literature on best practices in the selection interview, this paper describes a technology-based selection interview system. The process includes interviewer training and certification, and the construction of standardized interview guides. Linked to a common set of human abilities and skills, answers to the questions and probes are evaluated using behaviorally anchored rating scales for each of a number of competency elements. The process described can be used to help ensure quality interviewing practices in organizations of different sizes, structures, and levels of complexity. How to use this process to address various research objectives is also discussed.

\section{APPLIED PROBLEM TO BE ADDRESSED}

Interviews are the most frequently used selection tool across all countries, jobs, and job levels (McDaniel, Whetzel, Schmidt, \& Maurer, 1994; Salgado, Viswesvaran, \& Ones, 2001). Some estimates of interview use, especially for leadership purposes (Erker, Cosentino, \& Tamanini, 2010 ), indicate that nearly $100 \%$ of organizations use interviews at some stage in their selection process. Not all interview use yields equally valid decisions, however.

Often times, conducting interviews the right way means conducting interviews the painful way. Rather than take the time to prepare or identify an appropriate structured interview guide (i.e., complete with structured lead and probing questions organized around competencies required for job success and evaluation guidelines prepared in advance of the interview tied back to the aforementioned competencies), it is easier to simply bring candidates in for the interview and have an unstructured (or loosely structured) conversation, for example, "Tell me about yourself" or "Why did you apply for this job?" Similarly, organizations may have formal interviewer training programs, but these programs are likely either in-person or lengthy computer- or web-based programs. Although such programs can be extremely effective, they also present obstacles (e.g., time, cost) to training people the first time and then retraining them for refresher purposes in the future.

Thus, even when organizations are initially successful in training their interviewers to follow the organization's structured interview process, this adherence to the process fades over time and interviewers begin doing things the easy way. The reason for this, we believe, is that many organizations lack a system, technological or otherwise, to facilitate structure in their interview processes, a system that makes doing things the right way easy and convenient.

Although elements of good interviewing practice are fairly well accepted (Campion, Palmer, \& Campion, 1998; Levashina, Hartwell, Morgenson, \& Campion, 2014), interviews differ from many other forms of assessment in that most interviews are conducted in person with little use of technology (Reynolds \& Dichter, 2010; Scott and Lezotte, 2012) and often with the lack of structure and standardization that appear to be key to the validity and reliability of interviewer judgments. Most tests are now administered online or in some electronic form, including simulations (Lievens \& De Soete, 2012). It is our position that much of the effort in producing high-quality standardized interviews can be facilitated with the use of similar technology.

To gauge whether a technology-enabled system existed in the marketplace to facilitate (a) training and certification of interviewers and (b) interview guide creation, sharing, and storage, we prepared a brief description of a proposed web-based suite of tools and shared the description with a dozen human resource leaders in Fortune 100 and Fortune 500 organizations with two key questions: "Does this sound like an attractive offering - would it help your organization improve the effectiveness and efficiency of your interview processes?"; and "Is this offering duplicative of others that are already in the marketplace?" Overwhelmingly, our suppositions were correct; every organization indicated

Corresponding author:

Brad A. Chambers, Polaris Assessment Systems, Inc. Email: bchambers@polaristest.com

Phone: 513-755-0186 
that such an offering would help improve the effectiveness and efficiency of their interview processes, and no other systems currently available in the marketplace was viewed as offering a comprehensive a suite of tools.

With no existing technology-enabled systems to help organizations manage and facilitate effective and efficient interviewing, we formed a consortium of 11 organizations that believed the proposed solution would be beneficial. Member organizations represented a variety of industries, including healthcare, financial services, manufacturing, transportation, and mass media. In exchange for a modest monetary contribution to system development, member organizations received discounted use of the eventual product and the opportunity to shape the system's design and functionality through providing input and feedback on system specifications. Ultimately, this partnership with consortium organizations ensured that the eventual solution not only addressed best practices in effective and legally defensible interviewing but did so in a way that was consistent with how vastly different organizations wanted to use such a system.

\section{RESEARCH BASIS}

Many researchers have studied and documented the factors that drive interview effectiveness (for a thorough review see Levashina et al., 2014). The following are some research-based conclusions related to effective interview use:

1. Trained (vs. untrained) interviewers produce decisions that have greater validity (Huffcutt \& Woehr, 1999).

2. Structured interviews produce higher reliability and validity coefficients than unstructured interviews (McDaniel et al., 1994; Wiesner \& Cronshaw, 1988).

3. The construct targeted in an interview, and how consistently experts can make judgments about the construct, are important determinants of interview validity (Huffcutt, Conway, Roth, \& Stone, 2001).

4. Interview responses should be rated on jobrelated dimensions that are anchored behaviorally to help interviewers make reliable ratings that are focused on the targeted behavior (Honer, Wright, \& Sablynski, 2007; Maurer, 2002; Whetzel \& McDaniel, 2007).

5. Both situational and behavioral description interviews produce valid ratings, though behavioral description questions may be more valid than situational questions for lower level jobs (Huffcutt, Weekley, Wiesner, DeGroot, \& Jones, 2001).

6. Interview questions based on a job analysis should enhance validity and ensure that the interview includes relevant information (Campion et al., 1998).

7. Each candidate response in the interview should be evaluated on relevant competencies. Campion et al. (1998) provide several reasons why this is good practice, including likely increases in reliability, lowered memory requirements on the interviewer, and focusing the interviewer's evaluation on relevant behaviors.

Not surprisingly, these same characteristics that drive interview effectiveness are largely the same as those that drive legal defensibility of interviews (Williams, Schaffer, \& Ellis, 2013; Williamson, Campion, Malos, Roehling, \& Campion, 1997) with the exception of one additional driver of legal defensibility, which is clear documentation that supports the interview evaluations and decision.

Table 1 summarizes these drivers of interview effectiveness and legal defensibility. It was these characteristics upon which the system described in this paper was built.

\section{SOLUTION DESCRIPTION}

The system described in this paper is an online suite of tools designed to facilitate effective and legally defensible interviewing, and to help organizations exercise quality control over the interview process as it is conducted throughout the organization. The system contains two primary components, the first of which is a self-paced training program that takes most users just over 1 hour to complete and provides a "just the facts" and engaging overview of effective interviewing. The second component allows users to create, share, and store structured interview

TABLE 1 .

Effective and Legally Defensible Interviewing

\begin{tabular}{|c|c|c|}
\hline Characteristic & $\begin{array}{l}\text { Driver of } \\
\text { Effectiveness }\end{array}$ & $\begin{array}{c}\text { Driver of } \\
\text { Legal } \\
\text { Defensibility }\end{array}$ \\
\hline $\begin{array}{l}\text { 1. Structured format in which } \\
\text { all candidates are asked the } \\
\text { same set of questions }\end{array}$ & $\mathrm{X}$ & $\mathrm{X}$ \\
\hline $\begin{array}{l}\text { 2. Questions focused on } \\
\text { competencies that are rooted } \\
\text { in job requirements }\end{array}$ & $\mathrm{X}$ & $X$ \\
\hline $\begin{array}{l}\text { 3. Structured evaluation } \\
\text { standards, determined in ad- } \\
\text { vance of the interview, that } \\
\text { are tied to the competencies } \\
\text { measured }\end{array}$ & 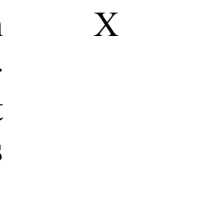 & $X$ \\
\hline $\begin{array}{l}\text { 4. Trained interviewers who } \\
\text { 1) ask appropriate questions, } \\
\text { 2) avoid inappropriate topics, } \\
\text { 3) treat all candidates equal- } \\
\text { ly, and 4) evaluate candidates } \\
\text { fairly }\end{array}$ & 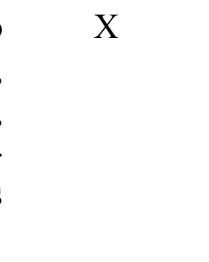 & $X$ \\
\hline $\begin{array}{l}\text { 5. Clear documentation that } \\
\text { supports the interview evalu- } \\
\text { ations/decision }\end{array}$ & & $X$ \\
\hline
\end{tabular}


guides, complete with evaluation guidelines and rating scales. Both of these components are housed within an administrative shell that controls and limits access to users based on assigned permissions.

\section{INTERVIEWER TRAINING}

The Effective Interviewer Training program consists of five modules that address various aspects of good interview practice. All modules are succinctly written to provide "just the facts" of interviewing best practices. The first module contains material on how to identify important job competencies that should form the basis of interview questions. The module also provides information about the legal constraints on the use of interview questions with examples of questions that can and cannot be asked in an interview to avoid legal challenges. This module contains material emphasizing the importance of asking job-related behavioral questions that are structured and systematically asked of all applicants. The module, like all modules in the set, ends with a "learning check" consisting of multiplechoice questions related to the material covered in the module.

In the second module, the interviewer is taught how to construct an interview. The module begins by reviewing the manner in which competencies are identified and then stresses the importance of asking either behavior-based past experience questions or hypothetical situation questions. Both types of questions are described and illustrated. Characteristics of a good interview question (e.g., job related, targeted to a single dimension, easy to understand, open ended) are described. Constructing an interview guide used in interviewing all candidates for a position is discussed, and its importance is stressed. Example behavior-based and hypothetical situation questions along with probes developed for a targeted marketing competency are displayed in Table 2. The importance of considering and formulating the nature of good and bad answers prior to the conduct of interviews and the construction of a behaviorbased rating scale of potential answers is described.

The third module emphasizes the use of a standard interview guide, attending to the interview physical environment, and opening the interview in a friendly but businesslike manner. It also discusses the use of different types of questions (behavior-based or hypothetical situation), the use of probes that address the context of the candidate's response, the candidate's behavior, and the outcome associated with the action. Finally, an appropriate ending to the interview is discussed.

The fourth module consists of various "special" topics including handling candidates who give short uninformative answers as well as those who are too talkative or get off the topic. The importance of nonverbal communication and its use is discussed as is the importance and content of note taking, including a focus on the situation, actions, and results provided in candidate answers. Also discussed is the use of multiple sequential interviews of the same person and how they should be coordinated to avoid repetitive questions and requiring the candidate to provide the same information multiple times. The advantages and conduct of interview panels are detailed.

Evaluation of interview candidates is the subject of the final module. The first point here is the importance of the development of evaluation standards prior to the conduct of the interview and the importance of evaluating candidates on each interview question. Defense against common rating errors includes listening carefully, taking good notes, and making ratings based on what is in your notes at the end of the interview. All ratings should be documented with data compiled from notes based on answers to interview questions.

TABLE 2

Behavioral Consistency and Hypothetical Situation Questions Designed to Measure a Targeted Marketing Competency

\section{Behavioral Consistency}

- Lead: "Please describe a marketing program you developed that was aimed to attract younger customers...ones who are, say, under the age of $30 . "$

- Supporting probes:

o "How did you determine the message you wanted to convey?"

o "What media did you use to reach them? Why"

o "If you encountered this situation again, would you do anything differently to be even more effective? Why/why not?"

Hypothetical Situation

- Lead: "Imagine that you needed to develop a marketing campaign that focused on selling widgets to the under-30s segment of the market. How would you go about deciding how to structure that campaign?"

- Supporting probes:

o "Why would you structure things that way?"

o "How could you be sure that your message would be attractive to the audience?"

o "Why did you decide to use the media you empha sized in your campaign? Why did you leave out (name of some of the media possibilities that were left out)?"

o "You provided one way of structuring the campaign. Let's say that it didn't seem to be working; what other approaches might you try?" 
TABLE 3

Two Questions (with Associated Feedback) from The Module 2 Learning Check

\section{Which of the following is a characteristic of a "good" interview question?}

(A) General (Incorrect. Good interview questions are specific, open ended, measurable, and address a single competency. The correct answer is "Open ended.")

(B) Open ended (Correct! Good interview questions are specific, open ended, measurable, and address a single competency.)

(C) Not measurable (Incorrect. Good interview questions are specific, open ended, measurable, and address a single competency. The correct answer is "Open ended.")

(D) Addresses more than one competency (Incorrect. Good interview questions are specific, open ended, measurable, and address a single competency. The correct answer is "Open ended.")

\section{Which of the following is a reason why a hypothetical situation interview question might be used?}

(A) If the candidates are inexperienced (Correct!)

(B) Hypothetical situation questions are more valid than behavioral consistency questions (Incorrect. Hypothetical situation and behavioral consistency questions are usually equally valid. The correct answer is "If the candidates are inexperienced.")

(C) Correct answers to hypothetical situation questions are easier to generate (Incorrect. The correct answer is "If the candidates are inexperienced.")

(D) Interviewees are more comfortable answering hypothetical situation questions (Incorrect. The correct answer is "If the candidates are inexperienced.")

Following the five training modules is a 20 -item certification exam that all interviewers must pass in order to be considered "certified." Organizations can require recertification after a specified period of time has elapsed (e.g., 1 year), and different organizations can require different levels of proficiency in order to "pass" the certification exam.

All of the interviewer training is brief and to the point, emphasizing dos and don'ts associated with interviewing best practices. Because all materials are delivered online, trainees can stop and start as needed. The organization can also monitor the successful completion of certification testing if this is desired.

Table 3 contains two questions and associated feedback from one of the learning checks. Similar questions are utilized in the final certification exam.

\section{CONSTRUCTION OF COMPETENCY MODEL AND LINKAGE TO COMPETENCY ELEMENTS}

If the organization has an existing competency model, users can proceed to link the competency model to competency elements (a comprehensive list of abilities and skills provided by the software). If there is no existing competency model, the system (i.e., through the use of the aforementioned training modules and a series of help resources) proceeds to provide instructions on how to develop such a model as the basis for an interview guide. The process of identifying competencies takes the organization's representatives through a series of steps that includes the identification of important job outcomes (e.g., positive customer service responses, call time adequate, following company policies might be outcomes for a customer service representative), delineation of key activities associated with each of these outcomes, and then the key competencies associated with these activities. These key activities or existing competency statements are linked to a common set of 82 competency elements derived from existing taxonomies (Fleishman \& Quaintance, 1984; Peterson, Mumford, Borman, Jeanneret, \& Fleishman, 1999), and these 82 competency elements are then tied to interview questions. Once the competency elements that are judged important to a particular job are identified, the interview guide is constructed by the user.

The aforementioned utilization of competency elements is a critical component of the system's flexibility. Because interview questions are tied to competency elements and the tool allows organizations to configure these elements into as many competency models as they would like, future changes to an organization's competency model(s) result in needing to update the competency-to-competency element mappings only. Doing so then reconfigures the entire system around the organization's newly defined competency model(s) rather than needing to remap the entire database of questions.

\section{QUESTION BANK AND CONSTRUCTION OF AN INTERVIEW GUIDE}

Once the important competency elements are identified, the user may use the question bank to construct an interview guide. The current question bank consists of 615 items that were written based on situational questions derived from a wide variety of jobs and used to develop situational judgment inventories, situational interviews, and performance evaluation instruments. They also included items from several sponsors of the project. All questions included in the question bank survived an extensive, multistep quality review process described in a subsequent section of this paper. Most competency elements have 10 or more questions linked to them. Part of the continuous improvement of this system includes the addition of items over time. 
TABLE 4

Examples of Competency Elements, Their Definitions, and Evaluation Guidelines

\begin{abstract}
Working with data: Compiling, coding, categorizing, organizing, calculating, tabulating, auditing, or verifying information or data.

- Ineffective. Works with data but often makes errors when doing so; does not check his/her work; is simply interested in getting the job done when working with data; does not recognize the likelihood or types of errors one can make when working with data

- Minimally effective. Can usually be counted on to perform tasks involving data accurately and efficiently; checks his/her work when working with data so that errors are not made; recognizes when and where data errors are likely and double checks these areas; recognizes the need for accuracy in dealing with data and behaves accordingly

- Highly effective. Is efficient and accurate in dealing with and organizing data; finds ways to monitor the quality and accuracy of activities involving data; is especially insightful in avoiding and detecting data errors; develops systems to monitor data accuracy and quickly corrects errors when they occur
\end{abstract}

Working with others: Working effectively with others as part of a group or team; projecting an air of friendliness, approachability, compassion, courtesy, and respect; building effective relationships with others; working with people who may be different from oneself; encouraging and building mutual trust and cooperation among team members.

- Ineffective. Prefers to work alone and is uncomfortable working in groups; others prefer not to work with him/her; does not build effective work relationships with others; is seen as unapproachable; is particularly resentful when asked to work with others that he/she sees as "different" in some way

- Minimally effective. Works effectively with others in a group; respects others' opinions and contributions; works in ways that promote group cooperation and mutual respect; is a welcome member in work groups; welcomes group members who may be "different" or express alternate points of view

- Highly effective. Works effectively in group contexts and is effective in making the most of others' contributions; is frequently sought ought to be part of work groups or teams when they are formed; actively seeks to include individuals who are "different" or who express alternate points of view; promotes a positive work atmosphere of courtesy and respect
If the users are accessing the question bank to construct an interview guide, they indicate the element(s) that they want to address, whether hypothetical situation or behavior-based (or both) types of questions are desired, and at what job level the questions should be targeted. A selection of questions is provided and the users specify which of these questions (and associated evaluation guidelines) they want to use, and it becomes part of the interview guide. This process is repeated for each of the important elements; when all desired elements have been covered, the interview guide is complete. The user has the option to edit these questions if desired to make them more applicable in a given context. This interview guide is then made available to potential interviewers at various sites in the organization. The primary user may provide editorial rights to some users if desired, but if a uniform process across units is desired this editing right would not be granted. Training on how to use the interview guide is provided in Module 3 of the training program described above.

\section{TABLE 5}

How the System Facilitates Effective and Legally Defensible Interviewing

\begin{tabular}{ll}
\hline $\begin{array}{l}\text { Drivers of interview } \\
\text { effectiveness and } \\
\text { legal defensibility }\end{array}$ & The system \\
\hline
\end{tabular}

Users create, store, and share struc-

Structured tured interview guides inside the

format and system so that a single guide can be questions used for all candidates applying for the same position

\begin{tabular}{|c|c|}
\hline $\begin{array}{c}\text { Questions } \\
\text { focused on } \\
\text { competencies }\end{array}$ & $\begin{array}{l}\text { Interview questions are tied to } 82 \\
\text { competency elements that are con- } \\
\text { figured to mirror the organization's } \\
\text { competency model(s); users select } \\
\text { questions based on the competen- } \\
\text { cies they are trying to measure }\end{array}$ \\
\hline $\begin{array}{l}\text { Structured } \\
\text { evaluation } \\
\text { standards }\end{array}$ & $\begin{array}{l}\text { Each competency element in the } \\
\text { system includes evaluation stan- } \\
\text { dards written at three levels of } \\
\text { performance (less than effective, ef- } \\
\text { fective, highly effective); users can } \\
\text { insert these standards directly into } \\
\text { their guides }\end{array}$ \\
\hline $\begin{array}{c}\text { Trained } \\
\text { interviewers }\end{array}$ & $\begin{array}{l}\text { The Effective Interviewer Training } \\
\text { program covers, from soup to nuts, } \\
\text { the entire interview process; asso- } \\
\text { ciated certification testing provides } \\
\text { documentation that all interviewers } \\
\text { have been certified }\end{array}$ \\
\hline
\end{tabular}




\section{EVALUATING CANDIDATE RESPONSES}

As mentioned above, each interview question is linked to one or more competency element (and associated evaluation guidelines), and interviewers are instructed to make ratings based on their notes from each question after the interview is complete. In making their ratings, they are asked to judge candidates' responses against the behavioral anchors associated with the element addressed in the question (see Table 4 for ineffective, minimally effective, and highly effective anchors for two competency elements). Consistent with findings from the research literature, ratings are made after the interview and separately for each item.

Thus, as a whole the system facilitates effective and legally defensible interviewing by making it easier for interviewers to do the right thing. Specially, Table 5 summarizes how the process addresses the key drivers of interview effectiveness and legal defensibility described previously.

\section{SOLUTION EVALUATION}

At this early stage in the system's existence (i.e., launched in the third quarter of 2014), system evaluation comes in two forms. The first form of evaluation relates to the question bank housing the set of 615 interview questions and associated probes. This question bank started as a set of 1,197 interview questions that were either contributed by consortium organizations or written by project personnel. The initial set of 1,197 questions was then reviewed and edited for clarity and redundancy, resulting in a reduced set of 829 unique interview questions. These 829 questions were then evaluated by a team of three industrial organizational psychologists with many decades of experience developing selection instruments and interviews. Evaluations were made using the following scales:

1. The quality of this item and its associated probes for measuring the noted competency element(s) is: [very high, high, moderate, low, very low]

2. Is this item and its associated probes appropriate for individual contributor jobs? [yes, no]

3. Is this item and its associated probes appropriate for supervisor and middle manager jobs? [yes, no]

4. Is this item and its associated probes appropriate for senior manager jobs? [yes, no]

In order to be retained for further consideration, a question's quality had to be rated as high or very high by at least two of the three industrial organizational psychologists. In addition, each question was rated using the same scales by an average of seven external industrial organizational psychologists and human resources professionals from the various consortium organizations. In order to be retained, at least $50 \%$ of external raters had to rate a question's quality as high or very high.

Finally, ratings of suitability for different job levels (i.e., individual contributor, supervisor/middle manager, senior manager) were used to flag questions as being relevant for these different job levels. In order to be flagged as relevant for a job level, at least two of the three industrial organizational psychologists and at least $50 \%$ of external reviewers had to agree that the question was relevant. Hence, after multiple rounds of review, scrutiny, and evaluation, the current set of 615 questions were judged to be of high quality and relevant to one or more job levels.

The second form of evaluation relates to the Effective Interviewer Training program. One consortium organization, a large, complex, global manufacturing organization headquartered in the United States, administers the training program to all hiring managers involved in the hiring of salaried employees. During initial rollout, the organization asked training participants to make a series of evaluation ratings of the program upon completion. After 600 plus participants had gone through the training program, evaluation ratings were tabulated.

As expected, Level-1 (Kirkpatrick, 1976) evaluations related to the quality of the training exceeded $95 \%$. With regard to the training being a good use of hiring managers' time, only $87 \%$ of individuals responded favorably. Although the development team was somewhat disappointed with this result, the consortium organization expressed great satisfaction, noting that similar ratings from hiring managers with regard to the vast majority of their training programs rarely exceed $50 \%$. Thus, despite being taken away from working on other high-priority activities, hiring managers evaluated the Effective Interviewer Training program as a good use of their limited time.

As time proceeds and additional client organizations use the system, the development team intends to conduct additional forms of evaluation related to increases in the effectiveness and efficiency of organizations' interviewing practices. The form of some of these evaluative and research efforts is described at the end of the paper.

\section{ETHICAL, LEGAL, AND PROFESSIONAL CONSID- ERATIONS}

As noted above, the characteristics that drive interview effectiveness are largely the same as those that drive legal defensibility of interviews (Williams et al., 2013; Williamson et al., 1997), and the system described in this paper helps facilitate interview processes that are consistent with these characteristics. First, interviews should utilize a structured format whereby all candidates are asked the same set of questions. In this system, authorized users create, store, and share structured interview guides inside the system so that a single guide can be used for all candidates applying for the same position. Second, interview questions should focus on competencies that are rooted in job requirements. The question bank includes 615 structured questions that 
are tied to 82 competency elements, and these competency elements can be configured to mirror an organization's competency model(s); users select questions based on the competencies they are trying to measure based on job requirements. Third, interviewers should utilize structured evaluation standards, determined in advance of the interview, that are tied to the competencies measured. Each competency element in the system includes evaluation standards written at three levels of performance (less than effective, effective, highly effective); users can insert these standards directly into their guides. Finally, interviewer training is critical to ensure that individuals conducting interviews (a) ask appropriate questions, (b) avoid inappropriate topics, (c) treat all candidates equally, and (d) evaluate candidates fairly. The Effective Interviewer Training program covers, from beginning to end, the entire interview process; associated certification testing provides documentation that all interviewers have been certified.

One module in the Effective Interviewer Training program discusses legal considerations related to interviewing. Because the interview system was designed for organizations around the globe, there are two versions of this module: a United States specific version that cites relevant federal laws (e.g., Civil Rights Act of 1991, Americans with Disabilities Act of 1990) and a generic global version that simply stresses the importance of asking job-relevant questions rather than cites specific laws.

Finally, the approach utilized to develop and refine the question bank was extremely rigorous, resulting in a robust library of questions that has been confirmed to be good measures of intended competency elements by both industrial organizational psychologists as well as human resources professionals across a variety of industries. We also intend to continuously update the question bank.

\section{DISCUSSION: CONTINUED RESEARCH AND DE- VELOPMENT}

Aside from the practical efficiencies and standardization that this system brings to organizations that employ multiple interviewers and at many different sites, the database being produced will allow for the reevaluation of many existing interview guidelines and the examination of new questions as well. Obviously, the collection of interrater reliability of judgments based on these interviews should be evaluated. We believe that interview guides constructed in this manner are content valid, but criterion-related validity studies should also be conducted.

The efficacy of behavior-based questions versus hypothetical situation questions for different types of competency elements can be assessed. The relative validity and reliability of the use of the interview to assess a wide variety of competencies and/or competency elements can be examined. If desired, the efficacy of the training modules in improving the conduct of the interviews could be evaluated. With some additional data collection, the degree to which interviewers continue to use standardized interview guides over time and the consequent impact on the quality of the interview would contribute to what we know about the implementation and life cycle of successful selection programs (Kehoe, Brown, \& Hoffman, 2012; Tippins, 2012).

The degree to which interview guide edits or revisions are allowed and the influence these changes may have on the validity and reliability of the interview is an interesting question that may have significant implications for applied use. Individual differences in the validity and reliability of interviewers could be ascertained as data accumulates. The impact of the use of probes may also represent an interesting question. Also of increasing interest to organizational researchers is the influence of the organizational unit on a variety of relationships in organizational behavior. This interest has not been reflected in most personnel selection research to date (Ployhart, 2012). Data being collected on many different organizations across interviewers and competency elements would provide the basis on which to consider many multilevel hypotheses, both for the developers of this system as well as researchers at other institutions.

In closing, we suggest that organizations seeking to develop their own interview management system keep the following in mind. First, the system should be grounded in the broad base of research that exists regarding effective and legally defensible interviewing. Table 1 and 5 describe the characteristics that drive effective and legally defensible interviewing, as well as how the system described in this paper addresses these characteristics. Second, the importance of consulting with eventual users of the system during its design and construction cannot be overstated. The system design team must understand how consumers of the system will want to use different features. Finally, as industrial organizational psychologists we recognize the importance of data-driven decisions, and any interview system of this nature should facilitate research and continuous improvement through data.

\section{REFERENCES}

Campion, M. A., Palmer, D. K., \& Campion, J. E. (1998). Structuring employment interviews to improve reliability, validity, and users' reactions. Current Directions in Psychological Science, 7, 77-82.

Erker, S. C., Cosentino, C. J., \& Tamanini, K. B. (2010). Selection methods and desired outcomes: Integrating assessment content and technology to improve entryand mid-level leadership performance. In J. L. Farr and N. T. Tippins (Eds.). Handbook of employee selection (pp. 721-740). New York, NY: Taylor and Francis.

Fleishman, E. A., \& Quaintance, M. K. (1984). Taxonomies of human performance. New York, NY: Academic Press, 
Inc.

Honer, J., Wright, C. W., \& Sablynski, C. J. (2007). Puzzle interviews: What are they and what do they measure? Applied HRM Research, 11, 79-96.

Huffcutt, A. L., \& Woehr, D. J. (1999). Further analysis of employment interview validity: A quantitative evaluation of interviewer-related structuring methods. Journal of Organizational Behavior, 20, 549-560.

Huffcutt, A. I., Conway, J. M., Roth, P. L., \& Stone, N. J. (2001). Identification and meta-analytic assessment of psychological constructs measured in employment interviews. Journal of Applied Psychology, 86, 897-913.

Huffcutt, A. L., Weekley, J. A., Wiesner, W. H., DeGroot, T. G., \& Jones, C. (2001). Comparison of situational and behavior description interview questions for higher-level positions. Personnel Psychology, 54, 619-644.

Kehoe, J., Brown, S., \& Hoffman, C. C. (2012). The life cycle of successful selection programs. In N. Schmitt (Ed.), Oxford handbook of personnel assessment and aelection (pp. 903-936). New York, NY: Oxford University Press.

Kirkpatrick, D. L. (1976). Evaluation. In R. D. Craig (Ed.), Training and development handbook (pp. 301-319). New York, NY: McGraw-Hill.

Levashina, J., Hartwell, C. J., Morgenson, F. O., \& Campion, M. A. (2014). The structured employment interview: Narrative and quantitative review of the research literature. Personnel Psychology, 67, 241-293.

Lievens, F., \& De Soete, B. (2012). Simulations. In N. Schmitt (Ed.). The Oxford handbook of personnel assessment and selection (pp. 383-410). New York, NY: Oxford University Press.

Maurer, S. D. (2002). A practitioner-based analysis of interviewer expertise and scale format as contextual factors in situational interviews. Personnel Psychology, 55, 307327.

McDaniel, M. A., Whetzel, D. L., Schmidt, F. L., \& Maurer, S. D. (1994). The validity of employment interviews: A comprehensive review and meta-analysis. Journal of Applied Psychology, 79, 599-616.

Peterson, N. G., Mumford, M. D., Borman, W. C., Jeanneret, P. R., \& Fleishman, E. A. (Eds.). (1999). An occupational information for the 21st century: The development of $O * N E T$. Washington, DC: American Psychological Association.

Ployhart, R. E. (2012). Multilevel selection and the paradox of sustained competitive advantage. In N. Schmitt (Ed.), Oxford handbook of personnel assessment and selection (pp.667-685). New York, NY: Oxford University Press.

Reynolds, D. H., \& Dichter, D. N. (2010). Technology and employee selection. In J. L. Farr and N. T. Tippins (Eds.). Handbook of employee selection (pp. 171-193). New York, NY: Taylor and Francis.

Salgado, J., Viswesvaran, C., \& Ones, D. (2001). Predictors used for personnel selection: An overview of constructs, methods, and techniques. In N. Anderson, D. S. Ones, H. K. Sinangil, \& C. Viswesvaran (Eds.), Handbook of industrial, work, and organizational psychology, Volume 1:
Personnel psychology (pp. 165-199). Thousand Oaks, CA: Sage.

Scott, J. C., \& Lezotte, D. V. (2012). Web-based assessments. In N. Schmitt (Ed.). The Oxford handbook of personnel assessment and selection (pp. 485-513). New York, NY: Oxford University Press.

Tippins, N. T. (2012). Implementation issues in employee selection testing. In N. Schmitt (Ed.), Oxford handbook of personnel assessment and selection (pp. 881-902). New York, NY: Oxford University Press.

Whetzel, D. L., \& McDaniel, M. A. (2007). Employment interviews. In D. L. Whetzel, D. L. and G. R. Wheaton (Eds.), Applied measurement methods in industrial psychology (pp. 185-205). Palo Alto, CA: Consulting Psychologists Press.

Wiesner, W. H., \& Cronshaw, S. F. (1988). A meta-analytic investigation of the impact of interview format and degree of structure on the validity of the employment interview. Journal of Occupational Psychology, 61, 275290.

Williams, K. Z., Schaffer, M. M., \& Ellis, L. E. (2013). Legal risk in selection: An analysis of processes and tools. Journal of Business and Psychology, 28, 401-140.

Williamson, L. G., Campion, J. E., Malos, S. B., Roehling, M. V., \& Campion, M. A. (1997). Employment interview on trial: Linking interview structure with litigation outcomes. Journal of Applied Psychology, 82, 900-912.

RECEIVED 8/26/2014 ACCEPTED 2/20/2015 